The sigh of the oppressed: The palliative effects of ideology are stronger for people living in highly unequal neighbourhoods

\author{
Nikhil K. Sengupta \\ University of Oxford \\ Lara M. Greaves, Danny Osborne and Chris G. Sibley \\ University of Auckland, NZ.
}

Word Count: 6730

Corresponding author:

Nikhil K. Sengupta

Department of Experimental Psychology

University of Oxford

South Parks Rd, Oxford OX1 3UD.

Email: nikhil.sengupta@psy.ox.ac.uk

Acknowledgements:

This research was supported by a Templeton World Charity Foundation Grant (ID: 0077) awarded to Chris Sibley and a Marie Curie Individual Fellowship awarded to Nikhil Sengupta (ID: 703316). 


\begin{abstract}
Ideologies that legitimise status hierarchies are associated with increased wellbeing. However, which ideologies have 'palliative effects', why they have these effects, and whether these effects extend to low-status groups remain unresolved issues. The present study aimed to address these issues by testing the effects of the ideology of Symbolic Prejudice on wellbeing among low- and high-status ethnic groups (4,519 Europeans and 1,091 Māori) nested within 1,437 regions in New Zealand. Results showed that Symbolic Prejudice predicted increased wellbeing for both groups, but that this relationship was stronger for those living in highly unequal neighbourhoods. This suggests that it is precisely those who have the strongest need to justify inequality that accrue the most psychological benefit from subscribing to legitimising ideologies.
\end{abstract}




\section{The sigh of the oppressed: The palliative effects of ideology are stronger for people living in highly unequal neighbourhoods}

"Religion is the sigh of the oppressed creature, the heart of a heartless world, just as it is the spirit of spiritless conditions."

- Karl Marx.

Marx's (1844) aphorism about Religion being "the opium of the people" is probably the most famous articulation of the idea that belief can be palliative. There is now evidence that not just religious belief, but many kinds of belief systems - or ideologies - are positively related to psychological wellbeing (e.g. Conservatism, Meritocracy, Benevolent Sexism; McCoy, Wellman, Cosley, Saslow, \& Epel, 2013; Jost, Wakslak, \& Tyler, 2008; Napier \& Jost, 2008; Napier, Thorisdottir \& Jost, 2010; Osborne \& Sibley, 2013). Consistent with Marx’s reasoning, System Justification Theory (Jost \& Banaji, 1994) proposes that these ideologies are palliative because they help people cope with the "spiritless conditions" in which they find themselves (Napier \& Jost, 2008). Specifically, they help people legitimise the inequality under which they suffer.

However, the burgeoning literature on the palliative effects of ideology raises some important questions that remain unresolved. First, the research to date has focussed on only a small subset of the many ideologies that can function to legitimise inequality (see Jost \& Hunyady, 2005), leaving scope for further exploration of which ideologies have palliative effects. Second, there is disagreement about the underlying psychological mechanisms giving rise to these effects. While System Justification Theory suggests that palliative effects reflect the function that ideology serves for 
legitimising inequality, several recent studies have challenged this interpretation (e.g. Schlenker, Chambers, \& Le, 2012; Jetten, Haslam \& Barlow, 2013). Third, it is unclear whether the palliative benefits of legitimising ideologies accrue equally to the victims and beneficiaries of inequality. There are reasons to expect either that these effects will be weaker among members of disadvantaged groups (e.g., Jost \& Thompson, 2000; Rankin, Jost \& Wakslak, 2009), or that they might be even stronger among these groups (see Laurin, Fitzsimmons \& Kay, 2011; McCoy et al., 2013).

Here, we aim to shed light on these questions by examining the link between ideology and wellbeing in a large, stratified national sample of high-and low-status groups (4,519 Europeans and 1,091 Māori, nested within 1437 neighbourhoods in New Zealand). More specifically, we test the palliative effects of an ideology that functions to legitimise inequality but has not yet been explored in the literature on this topic: Symbolic Prejudice. We also present a crucial test of inequality-legitimation account of palliative effects. If the reason why certain ideologies are positively associated with wellbeing is that they help people cope with inequality, then this association should be stronger for those living in more unequal contexts. Finally, we model a three-way, cross-level interaction which tests whether the strength of the palliative effects of ideology in more versus less equal conditions also differs based on whether people belong to a high- or low-status group.

\section{The Effects of Inequality}

Inequality between individuals and groups is both a historical feature of human societies and a contemporary reality (Piketty, 2014; Sidanius \& Pratto, 1999; Wilkinson \& Pickett, 2009). It is, however, an uncomfortable reality. Wilkinson and Pickett's (2009) ground-breaking analysis showed that people who live in societies characterised by large disparities in wealth and income fare worse on a wide range of 
social and psychological indicators compared to people in more equal societies. For example, in Western countries with high levels of inequality, people report lower levels of happiness and social trust (e.g. Delhey \& Dragolov 2014; Fahey \& Smyth 2004; Layte 2011). Even within nations, people who live in more unequal areas (e.g. regions or neighbourhoods) report lower wellbeing and self-esteem than those in less unequal areas, adjusting for personal income (e.g. Alesina, Di Tella, \& MacCullough, 2004; Osborne, Sibley \& Sengupta, 2015).

Research exploring why inequality is associated with these negative outcomes is still in its infancy. However, the most empirically validated explanation in the extant literature is that inequality conflicts with fundamental human concerns for fairness and justice (see Schneider, 2015). As early as 12 months, infants show a clear preference for the fair distribution of resources (Geraci \& Surian, 2011; Sloane, Baillargeon, \& Premack, 2012), and this preference continues into adulthood (Kahneman, Knetsch, \& Thaler, 1986; Norton \& Ariely, 2011; Smith \& Tyler, 1996). Large empirical literatures on System Justification Theory (SJT; Jost \& Banaji, 1994) and the Just World Hypothesis (JWH; Lerner, 1980) have shown that people are generally motivated to perceive their social world as fair (Liviatan \& Jost, 2014; Jost et al., 2004; van de Bos \& Lind, 2002).

When the motive to view society as fair is left unfulfilled by people's social reality, they react negatively. Experiments by game theorists suggest that negative reactions to violations of fairness are a human universal (Fehr \& Rockenbach, 2003; Henrich, 2000; Kahneman et al., 1986). At the societal level, Oishi, Kesebir and Diener (2011) found that Americans reported lower average happiness during years when inequality was higher, and that this effect was mediated by perceptions of 
unfairness. These findings indicate that one reason that inequality is uncomfortable is because it leads people to question the fairness of the system under which they live. The Palliative Function of Ideology

System Justification Theory proposes that one way people cope with the discomfort induced by inequality is to endorse ideologies - shared sets of beliefs, norms and prescriptions for making sense of one's sociopolitical context - that make unequal social structures seem fair (Jost et al., 2008; Jost, Federico, \& Napier, 2009; Jost \& Hunyady, 2005). The main hypothesis derived from this proposition is that ideologies that legitimise inequality will be positively associated with wellbeing.

One such ideology that has received considerable empirical attention is generalised Conservatism, with numerous studies showing that conservatives are happier than liberals (Napier \& Jost, 2008; Schlenker et al., 2012; see Onraet, Van Hiel, \& Dhont, 2013 for a meta-analytic review). A system-justification account of this finding is that conservatives are better able to legitimise the inequality in their societies (Jost, Glaser, Kruglanski \& Sulloway, 2003; Napier \& Jost, 2008). However, other researchers have questioned this interpretation, arguing that Conservatism is merely correlated with other factors that predict positive psychological adjustment (e.g. socioeconomic status, religiosity, moral clarity and optimism; Jetten et al., 2013; Schlenker et al., 2012).

From a system-justification perspective, Conservatism is considered a legitimising ideology because it reflects support for an inherently unequal status quo (Napier \& Jost, 2008). However, we argue that much of the uncertainty and disagreement over how to interpret the effects of Conservatism on wellbeing stems from the fact that this ideology is too broad to speak directly to the legitimizing function of people's beliefs. For example, in addition to indexing support for unequal 
systems, Conservatism also indexes other types of ideological positions that do not directly relate to the legitimation of inequality (e.g. support for authority and tradition, resistance to change; Duckitt, 2001; Jost et al., 2003). Therefore, a better test of the inequality-legitimation explanation for palliative effects would be whether ideologies with content that is more specific to legitimising inequality also show positive associations with wellbeing.

\section{Different Types of Legitimising Ideologies}

One way of making inequality seem fair is to frame the victims of inequality as deserving of their disadvantage. There are several ideologies that serve this function. For example, the Belief in a Just World (BJW; Lerner, 1980) proposes that world is organised in such a way that people get what they deserve and deserve what they get; the Protestant Work Ethic (PWE; Furnham, 1982) proposes that success is merely the result of hard work; and Meritocracy (McCoy \& Major, 2007) proposes that people's outcomes are determined by their individual merit. Holding these types of beliefs allows people to derogate the victims of inequality as not being deserving enough, hard-working enough, or meritorious enough to have reaped better socioeconomic outcomes (see Hafer \& Chroma, 2009; Quinn \& Crocker, 1999; McCoy \& Major, 2007). Thus, inequality can be explained as resulting from legitimate differences between individuals (e.g. differences in deservingness, work ethic, or merit), rather than from unfair social structures (see Major, 1994). Consistent with the inequality-legitimation account of palliative effects, all of these ideologies have been shown to relate positively to wellbeing (Jost, Pelham, Sheldon \& Sullivan, 2003; Kluegel \& Smith, 1986; McCoy et al., 2013; O’Brien \& Major, 2005; van der Toorn, Berricks \& Jost, 2010). 
Derogating the victims of systemic disadvantage is not the only way to make societal inequalities seem fair. Ideologies that ascribe complementary positive and negative traits to low-status groups can make it seem like there is balance in society people might be disadvantaged, but it is not "all bad" (Jost, Kay \& Young, 2005). One such ideology is Benevolent Sexism (BS), which legitimises gender inequality by stereotyping women as "weak but wonderful” (Glick \& Fiske, 2001). Again, consistent with the inequality-legitimation account of palliative effects, BS has been shown to predict greater life satisfaction among both men and women in 32 countries (Napier, Thorisdottir \& Jost, 2010). Crucially, recent research suggests that these palliative effects of BS are mediated by increased perceptions that society is fair and just (Connelly \& Heesacker, 2011; Hammond \& Sibley, 2011).

Finally, more general ideologies that frame society as being fair despite existing inequalities (i.e., diffuse System Justification; Kay \& Jost, 2003) or that frame inequality as being normative and desirable (i.e., Social Dominance Orientation; Sidanius \& Pratto, 1999) have also been shown to have palliative effects (e.g., Rankin et al., 2009; Wakslak, Jost, Tyler \& Chen, 2007). Taken together, the fact that all of these ideologies -with content more specific to legitimising inequality than generalised Conservatism- show positive associations with wellbeing, suggests that the palliative function of ideology lies in its ability to help people cope with the sense of unfairness that is triggered by living in an unequal society.

\section{The Present Study}

The present study aims to extend the literature reviewed above by testing the palliative effects of another legitimising ideology that has not yet been explored in terms of its association with wellbeing - i.e., Symbolic Prejudice (Kinder \& Sears, 1981). Symbolic Prejudice indexes the belief that disadvantaged groups should not 
receive any systematic compensation for their poorer social outcomes (e.g., in the form of affirmative action; see Sears \& Henry, 2003). This ideology has been chosen because it is the logical conclusion of applying victim-blaming beliefs about the deservingness of individuals (e.g. Meritocracy, PWE) to the deservingness of groups. A corollary of the belief that inequality is the result of fair processes whereby more deserving individuals reap greater societal rewards is that disadvantaged groups have poorer outcomes because the individuals belonging to these groups are less deserving (see Peterson, 2015). Indeed, there is considerable empirical evidence that a core component of Symbolic Prejudice is the belief that individuals belonging disadvantaged groups (e.g. Black Americans) possess traits that make them undeserving (e.g. laziness/incompetence; see Sears \& Henry, 2005 for a review). Our primary argument is that if ideologies about individuals such as Meritocracy, PWE and JWB have palliative effects because they legitimise inequality as arising from fair processes, then an ideology about groups such as Symbolic Prejudice that relies on the same logic of legitimation (i.e., that the victims of inequality are responsible for their own disadvantage) should also have similar palliative effects. If this were to be the case, then it would add further support to the notion that the palliative function of ideology lies in its ability to frame existing inequality in society as being fair and just.

Apart from showing that ideologies with content specific to the legitimation of inequality have palliative effects, a crucial test of the inequality-legitimation account of these effects would be whether they are more pronounced among those living in highly unequal conditions. The inequality people see around them should lead them to experience a stronger sense of unfairness about the system under which they live than those living in more equal conditions (e.g. Oishi et al., 2011). Therefore they would 
have the most to gain, psychologically, from belief systems that help them to frame this inequality as being fair. Here, we will test this idea directly for the first time by analysing differences in the strength of palliative effects among people living in more versus less equal neighbourhoods.

Finally, the present study also aims to address a highly controversial and unresolved question about the palliative effects of ideology - i.e., the extent to which these effects will be observed among members of disadvantaged groups. The fact that advantaged-group members accrue the palliative benefits of legitimising ideologies is understandable because their motive to maintain their group's position aligns with their motive to perceive the social world as fair (Jost, Burgess \& Mosso, 2001). Thus, endorsing ideologies that frame inequality as fair allows dominant group members to continue reaping the benefits of being atop the social hierarchy, while simultaneously avoiding the discomfort caused by the unfairness inherent in that hierarchy (Wakslak et al., 2007). However, whether subordinate groups derive psychological benefits from beliefs that legitimise their own disadvantage is less clear, because the interests of these groups are not served by providing ideological support to unequal systems. Indeed, this conflict between their self- and group-interests of the one hand, and their need to legitimise the inequality they are exposed to on the other, can have negative psychological consequences for members of disadvantaged groups. For example, Jost and Burgess (2000) found that members of low-status groups held more ambivalent attitudes towards their own group, and that this ambivalence increased as a function of their need to legitimise inequality. More directly, Jost and Thompson (2000) showed that while members of advantaged groups who subscribed to the legitimising ideology of SDO reported higher self-esteem and lower levels of depression, members of disadvantaged groups who subscribed to this same ideology 
reported lower self-esteem and higher depression. Further, Rankin et al. (2009) showed that while framing the American system as being fair and just had palliative effects for European Americans, these effects were weaker and sometimes in the opposite direction among African Americans. These findings imply that the disadvantaged might not reap the same palliative benefits from legitimising ideologies as the advantaged do.

Nevertheless, there are several studies that find palliative effects even among low-status groups (Hammond \& Sibley, 2011; Jost et al., 2003; McCoy et al., 2013; Napier et al., 2010; Obrien \& Major, 2005). What is more, there are reasons to expect that these palliative effects might sometimes be even stronger among such groups. To understand why this might be the case, it is necessary to consider the different functions legitimising ideologies serve depending on whether one is a victim or a beneficiary of inequality.

The primary discomfort-inducing implication of inequality for the beneficiaries of inequality (i.e., high-status groups) is that they have potentially gained an unfair advantage over others (Laurin, Fitzsimmons \& Kay, 2011; Jost, et al., 2008). Therefore, the palliative function of legitimising ideologies for members of these groups lies primarily in their ability to reduce the aversive affective consequences of having accrued this kind of unfair advantage. Accordingly, Wakslak et al. (2007) showed that the relationship between ideology and wellbeing among the advantaged was mediated by reduced moral outrage and guilt.

However, for members of low-status groups, the problem of inequality is more personal. These are the people who are disproportionately more likely to have had their own outcomes affected negatively by social stratification. For them, inequality implies an unfair disadvantage faced by themselves and their group. Acknowledging 
this implication can reduce the degree to which members of low-status groups feel like they have control over their own outcomes (Laurin et al., 2011). If people do not feel in control of their outcomes, they cannot plan for the future with confidence (Feather, 1982; Wigfield \& Eccles, 1992), and thus, cannot enact strategies to improve their condition. Therefore, the primary palliative benefit of legitimising ideologies for low-status groups should lie in their ability to provide the sense of control necessary to engage in long-term goal pursuit.

Consistent with this reasoning, Laurin et al. (2011) found, across five studies, that the legitimising ideology of Meritocracy predicted an increased commitment to long-term goals among members of low-status groups, but not among members of high-status groups. They also found that the reason these beliefs increased goalcommitment among the disadvantaged was that they reduced expectations of being treated unfairly. In another study, McCoy et al. (2013) showed that the palliative benefits of Meritocracy for low-status groups were fully explained by increased perceptions of personal control.

These findings suggest that legitimising ideologies serve a self-regulatory function for the disadvantaged that they do not serve for the advantaged. In addition to making people feel less morally outraged by inequality (e.g. Wakslak et al., 2007) these ideologies have the potential to help the disadvantaged feel a greater sense of personal control over their own outcomes (Laurin et al., 2011). Thus, the palliative effects of legitimising ideologies might in fact be stronger for disadvantaged relative to advantaged individuals. Given the paucity of empirical data comparing the strength of palliative effects between advantaged and disadvantaged groups, along with theoretical reasoning that seems to support a pattern in which these effects are either 
stronger or weaker among the latter, we leave this an open question and test the interaction between group status and ideology predicting wellbeing.

We additionally test a three-way interaction between inequality, ideology and group-status. This is because while inequality might indeed trigger concerns over fairness for both high- and low-status groups, the preceding analysis suggests that it might trigger an additional concern among low-status groups that they do not have personal control over their own outcomes in the unequal system. Thus, the enhanced palliative potential of legitimising ideologies for low-status groups might be especially pronounced under conditions of high inequality. On the other hand, in more equal conditions the disadvantaged might lose this particular psychological incentive to legitimise the very systems that disadvantage them (i.e., the incentive to gain a sense of personal control over their outcomes), and for them, the psychological costs of legitimation might begin to outweigh the benefits (e.g., see Jost \& Thompson, 2000). In this scenario, the difference between the strengths of palliative effects in more versus less equal conditions would be greater among disadvantaged groups than advantaged groups.

The groups in the present analysis are European New Zealanders (i.e., the ethnic-majority group) and Māori (i.e., the indigenous peoples of New Zealand), drawn from a large, stratified, national sample of advantaged and disadvantaged groups in New Zealand (i.e. The New Zealand Attitudes and Values Study; NZAVS). The colonial history of New Zealand has left contemporary Māori at a severe socioeconomic disadvantage relative to their European counterparts (King, 2007; Walker, 1990). For example, Māori suffer higher mortality, incarceration and unemployment rates, have lower median incomes and report lower wellbeing 
compared to Europeans (The Social Report, 2010; Ajwani, Blakely, Robson, Tobias, \& Bonne, 2003). Thus, Māori are unquestionably a low-status group in New Zealand. In addition to having large samples of both Europeans and Māori $(\mathrm{N}=4,519$ and 1,091, respectively), our dataset includes information about the objective levels of income inequality across 1,437 regions of the country. The richness of these data provide us with an unprecedented opportunity to model how the level of inequality in a people's immediate context interacts with their group-status and ideological beliefs to predict wellbeing.

\section{Hypotheses}

To summarise our analysis thus far, inequality has negative consequences for people's wellbeing in large part because it conflicts with a general motive for fairness (e.g., Oishi et al., 2011). Based on this we predict:

H1: There will be a negative relationship between the levels of inequality in people's immediate context and their levels of subjective wellbeing.

Second, the literature on the palliative effects of ideology suggests that the discomfort produced by inequality can be reduced by subscribing to ideologies that legitimise it by framing the victims of inequality as being responsible for their own outcomes (e.g. McCoy et al., 2013). Therefore, we predict:

H2: There will be a positive relationship between the degree to which people subscribe to the legitimising ideology of Symbolic Prejudice and their subjective wellbeing.

Third, if the palliative effects of ideology reflect the function that ideology serves to help people cope with the inequality then they should be stronger for people living in more unequal conditions. Based on this, we predict: 
H3: The positive relationship between Symbolic Prejudice and subjective wellbeing will be stronger in neighbourhoods with a higher inequality compared to neighbourhoods with lower inequality.

Fourth, given the lack of clear indication about whether the palliative effects of ideology will be stronger, weaker, or similar across groups of different status, we test the interaction between ethnicity and Symbolic Prejudice predicting subjective wellbeing. Finally, we test whether the difference between the palliative effects of ideology in more versus less equal contexts is smaller or larger among members of a disadvantaged group (i.e. Māori) by modelling a three-way interaction between neighbourhood-level inequality, Symbolic Prejudice and ethnicity.

\section{Method}

\section{Sampling Procedure}

Data for the present analyses are drawn from the New Zealand Attitudes and Values Study (NZAVS) ${ }^{1}$. The first wave of the NZAVS (collected in 2009) contained responses from 6518 participants randomly sampled from the 2009 New Zealand electoral roll. The electoral roll is publicly available for scientific research and, in 2009, contained 2,986,546 registered voters. This represented all citizens over 18 years of age who were eligible to vote (regardless of whether they chose to vote), barring people who had their contact details removed due to specific case-by-case concerns about privacy. In sum, postal questionnaires were sent to 40,500 registered voters (i.e., roughly $1.36 \%$ of all registered voters in New Zealand). The overall response rate (adjusting for the address accuracy of the electoral roll and including anonymous responses) was $16.6 \%$.

\section{Census Area Units}


The New Zealand census provides rich information about each area unit/neighbourhood of the country and makes these data available for research purposes. The smallest of these area units are "meshblocks". As noted above, meshblocks make up larger census area units (which were our focus in this paper). The geographical size of these census area units differs depending on population density, but each unit tends to cover a region containing a median of 2097 residents $(M=2,253, S D=1,587$, range $=3-9,027)$. These area units are thus roughly the size of small neighbourhoods (in terms of population). Although they do not represent formal geographic neighbourhoods, they provide a novel source of information about the population characteristics of the immediate 2,000-odd people living in each participant's region of residence.

\section{Participants}

Of the entire sample, only participants who identified as New Zealand European or Māori-and who provided complete data for our variables of interestwere included in our analysis. This subsample contained responses from 5,592 participants (i.e., $85.8 \%$ of the overall sample). Our analysis of Europeans was based on 4,504 participants nested within 1,337 census area units (3.37 per unit), whereas our analysis of Māori was based on 1,088 participants nested within 690 area units (1.58 per unit). Collapsing across Māori and non-Māori respondents, our sample resided in 1,437 distinct census area units.

\section{Procedure for Calculating Neighbourhood Inequality}

We calculated regional Gini coefficients for the net 1,437 census area units in New Zealand in which our participants resided. Thus, this analysis spanned the vast majority of all area units in New Zealand. The rare cases where there were missing 
Gini coefficients for area units $(n=372)$ from our sample occurred because some units in rural areas have a very small number of (or, in some cases, no) residents.

We used data from the 2006 New Zealand census to determine the number of people in each census area unit whose household income fell within each of the following household income bands provided by Statistics New Zealand: (a) less than $\$ 5,000$, (b) $\$ 5,001-\$ 10,000$, (c) $\$ 10,001-\$ 20,000$, (d) $\$ 20,001-\$ 30,000$, (e) $\$ 30,001-$ $\$ 50,000$, and (f) $\$ 50,001$ and above. Because the census only provides information on broad income bands, we took the lower value within each band and treated these points as known values when interpolating a Lorenz curve, as outlined in Equation 1.0 (see Chaudhary, 2009, p. 126):

$$
G_{1}=1-\sum_{k=1}^{n}\left(X_{k}-X_{k-1}\right)\left(Y_{k}+Y_{k-1}\right)
$$

Where, $X_{k}$ is the cumulated proportion of the population variable, for $k=0, \ldots, n$, with $X_{0}=0, X_{n}=1$; and $Y_{k}$ is the cumulated proportion of the income variable, for $k=$ $0, \ldots, n$, with $Y_{0}=0, Y_{n}=1$.

This formula provides an approximate estimate of income inequality, as we do not employ advanced techniques such as approximating a quadratic function or other smoothing procedures. Also, because income values above $\$ 50,001$ were rounded down to $\$ 50,001$, our estimate systematically underestimates the actual level of inequality in each region. Despite these limitations, our Gini estimate offers a reasonable Lorenz curve approximation of inequality given the available data from the census on household income for each area unit of the country. As with a standard Gini coefficient calculated at the level of the nation, scores on our Gini estimate could range from 0 (complete equality) to 1 (complete inequality). Thus, higher scores reflect greater levels of regional-level inequality. Within our study, Gini values 
ranged from .33 to $.73(M=.47, S D=.05)$. We additionally included the population size of each census area unit as a covariate in our model due to the high degree of variation in the number of people in each unit (Range: 3-9,027).

\section{Questionnaire Measures}

Ethnicity was measured using the standard wording and coding system employed by the New Zealand census: "Which ethnic group do you belong to? (mark the space or spaces which apply to you)". Symbolic Prejudice was measured using the following three items drawn from a longer, New Zealand-specific scale developed by Sibley and Wilson (2007): (a) "we are all New Zealanders and the law should not make provision for minority groups because of their ethnicity", (b) "true equality can be achieved only once we recognise that some ethnic groups are currently more disadvantaged than others and require additional assistance from the government" (reverse-scored), and (c) "we are all one nation and we should all be treated the same. No one should be entitled to anything more than the rest of us simply because they belong to one particular ethnic group." Each item was rated on a 7-point scale with anchors at 1 (strongly disagree) and 7 (strongly agree) and averaged to form a measure of meritocratic beliefs $(\alpha=.69)$. Personal wellbeing was measured using ratings of satisfaction on a $0-10$ scale ( 0 - completely dissatisfied; 10 - completely satisfied) for the following four items: "Your health"; "Your personal relationships"; "Your standard of living"; "Your future security" $(\alpha=.73)$. We also adjusted for the effects of household income, to show that our predicted pattern reflected the effects of inequality and group-status, rather than personal financial status. Finally, other demographic covariates, specifically, age, gender $($ women $=0$, men $=1)$ and education (none $=-2$, some high school $=-1$, diploma/certificate $=0$, undergraduate $=1$, postgraduate $=2$ ) were also included as covariates in the model at the within 
level, while population size of the area units was included as a covariate at the between level.

\section{Results}

We constructed a multilevel model examining the relationship between Symbolic Prejudice and personal wellbeing moderated by ethnicity, adjusting for the logarithm of household income, gender, age, education (at the within-level) and the population size of census area units (at the between-level). We modelled the intercept and slope for Symbolic Prejudice as random effects, thus allowing them to vary across census area units. Symbolic Prejudice, ethnicity, the logarithm of household income, gender, age and education were centred at their respective group means. We included regional inequality (Gini coefficients) as a between-level variable moderating the association between Symbolic Prejudice and wellbeing, and moderating the interaction between Symbolic Prejudice and ethnicity (i.e. a threeway, cross-level interaction). Gini coefficients and the population sizes of area units were centred at their respective grand means. Population size was divided by 1000 such that each unit of the variable represents 1000 individuals. Descriptive statistics and correlations between all variables at Level 1 are presented in Table 1.

In line with Hypothesis 1, between-level analyses indicated that regional inequality was negatively associated with personal wellbeing. Further, in support of Hypothesis 2, Symbolic Prejudice was positively associated with personal wellbeing. At the within-level of analysis, household income (log), age and education were also positively associated with wellbeing. Men reported significantly higher wellbeing than women, and Europeans reported significantly higher wellbeing than Māori. However, the interaction between ethnicity and Symbolic Prejudice was non- 
significant. Thus, the palliative effect of Symbolic Prejudice appears to be similar in magnitude across members of low- or high-status groups.

At the between-level of analysis, area-unit population was not significantly related to wellbeing. Crucially, consistent with Hypotheses 3, there was a significant cross-level interaction between Symbolic Prejudice and regional inequality predicting wellbeing (See Table 2 for the full set of regression coefficients). However, the threeway interaction between inequality, Symbolic Prejudice and ethnicity was nonsignificant. This indicated that the way in which the strengths of the palliative effects of Symbolic Prejudice varied as a function of contextual inequality was similar for members of both low- and high-status groups.

To probe the interaction between Symbolic Prejudice and regional inequality, we estimated simple slopes for the effect of Symbolic Prejudice at conditional Gini values of .47 (the grand mean), .42 (.05 below the mean) and .57 (.10 above the mean). We opted for these lower and upper values because the distribution of Gini coefficients was skewed, and these values represented the lower and upper decile values (i.e., the $10^{\text {th }}$ and $90^{\text {th }}$ percentile points) of our measure of inequality.

As shown in Figure 1, Symbolic Prejudice was most strongly positively associated with personal wellbeing at high conditional values of inequality $(b=.170$, $\mathrm{se}=.034, \mathrm{z}=5.07, \mathrm{p}<.001,95 \% \mathrm{CI}[.104, .236])$. The simple slope for the effect of Symbolic Prejudice on wellbeing at moderate conditional values of inequality was also significant, but smaller in magnitude $(b=.124, \mathrm{se}=.020, \mathrm{z}=6.156, \mathrm{p}<.001$, $95 \%$ CI $[.085, .164])$ while the simple slope at low conditional values of inequality was the smallest in size $(b=.080, \mathrm{se}=.026, \mathrm{z}=3.040, \mathrm{p}=.002,95 \%$ CI [.028, .130]). Thus, in line with Hypothesis 3, the greater in contextual inequality the stronger the palliative effects of the ideology of Symbolic Prejudice. 


\section{Discussion}

This is the first study of its kind testing the palliative effects of Symbolic Prejudice, and testing how these effects differ between advantaged and disadvantaged groups, as well as between those living in more versus less equal conditions. First, we found that people who lived in more unequal neighbourhoods reported lower wellbeing, on average, than those who lived in more equal neighbourhoods. This is consistent with prior work showing that inequality is negatively associated with wellbeing, especially in Western nations (Alesina et al., 2004; Oishi et al., 2011; Osborne, Sibley \& Sengupta, 2015).

Second, we found a positive association between Symbolic Prejudice and wellbeing. This finding is consistent with the notion that ideologies that legitimise inequality have psychological benefits for those who subscribe to them (e.g., Napier \& Host, 2008; Wakslak et al., 2007). It also extends this literature on palliative effects by showing that Symbolic Prejudice, which legitimises inequality by framing certain groups as undeserving has similar psychological consequences as ideologies that frame certain individuals as undeserving (e.g. Meritocracy, PWE). Moreover, given that the content of Symbolic Prejudice is specific to the nature of group-based disadvantage, our results add greater support to inequality-legitimation account of palliative effects. While it is quite possible that generalised Conservatism has palliative effects because it is associated with other factors that predict positive adjustment (as argued by Schlenker et al., 2011), or because it reflects higher status which gives people access to a larger number of social identities (as argued by Jetten et al., 2013), these explanations cannot as easily account for the palliative effects of Symbolic Prejudice. 
Third, we found that contextual inequality moderated the relationship between Symbolic Prejudice and wellbeing. More specifically, the positive association between Symbolic Prejudice and wellbeing was stronger for people living in more unequal neighbourhoods. This supports our argument that subscribing to legitimising ideologies can help assuage the discomfort triggered by inequality. People might generally have an awareness that inequalities exist in their societies and therefore legitimising ideologies serve a palliative function for everyone (hence the main effect of Symbolic Prejudice on wellbeing). However, those living in more unequal neighbourhoods are directly confronted with the reality of inequality, making it more salient, thereby increasing the hedonic 'pay-off' of ideologically legitimising it. This pattern of results adds further weight to the idea that the reason why ideology exerts palliative effects is because certain belief systems help people cope with the inequality they are exposed to.

Finally, we did not find any ethnic-group differences in the strength of the palliative effects of Symbolic Prejudice. We tested for these differences because of conflicting indications in the literature that they might either be stronger or weaker among low-status groups compared to high-status groups. However, the fact that these effects are similar in size for members of both kinds of groups is informative in itself. Despite the fact that the content of Symbolic Prejudice runs directly counter to the group interests of Maori (by suggesting that Maori do not need any systematic compensation for historical injustices they have suffered), they seemed to gain a similar degree of palliation from this ideology as the group that benefits materially from it (i.e. Europeans). 
This has negative implications for the prospects of social changes towards equality. This kind of social change most often occurs through the political mobilisation of members of historically disadvantaged groups (e.g. see Reicher, 2007). In order for these groups to become mobilised, they need to feel a sense of injustice, anger and moral outrage over the unfairness their group is subjected to (van Zomeren, Spears, Fischer \& Leach, 2004). However, if they subscribe to belief systems that soften the blow of inequality, they might be less likely to find the political will to engage in the difficult actions required to improve their group's position. This is the central point of Marx's opium metaphor - certain beliefs can sedate those who are living in conditions that they would otherwise be motivated to rebel against. This is why when he advocates criticising these sedative belief systems he does so in the hope that people will shake off their comforting illusions, and create the kind of reality in which they do not need to use false beliefs as a coping mechanism:

"Criticism has plucked the imaginary flowers on the chain not in order that man shall continue to bear that chain without fantasy or consolation, but so that he shall throw off the chain and pluck the living flower" (Marx, 1844).

\section{Strengths and Limitations}

It must be acknowledged that the cross-sectional data in this study does not allow for a definitive test of the causal direction of the ideology-wellbeing relationship. For example, it could be that people with greater wellbeing are apt to endorse Symbolic Prejudice (see Schlenker, Chambers, \& Le, 2012 for a similar argument relating to the ideology of generalised conservatism). However, the interaction we found between inequality and ideology would be harder to explain from this perspective. We do not readily see why subjective wellbeing should increase 
Symbolic Prejudice more strongly among those who live in relatively unequal areas than among those who live in relatively equal areas. Nonetheless, future research using experimental and longitudinal designs will be able to speak more definitively to the causal direction hypothesised here.

Another limitation of our analysis is that we have operationalised regional inequality in terms of income, whereas group status and ideology were operationalised in terms of ethnicity. Ideally, we would have attempted to show that those living in areas with the greatest ethnic inequality gained the most palliative benefits from an ideology that legitimises the inequality that exists along ethnic-group lines. However, we were unable to construct a measure of ethnic inequality, for want of regional-level data on the income distribution across ethnic-groups.

Nonetheless, there are at least two reasons why we think our ability to draw conclusions about the effects of inequality might not be substantively mitigated by this lack of alignment. First, our argument about inequality is essentially an argument about how exposure to social stratification makes societal unfairness salient. Therefore, the actual dimension along which that stratification exists is not particularly important for the case we are trying to make. As long as inequality triggers concerns about the fairness of status differences between groups (see Johnson, Leedom \& Muhtadie, 2012; Oishi et al., 2011), it should affect people in the way we hypothesise. Consistent with this idea, research in New Zealand has shown that exposure income inequality does in fact correlate positively with perceptions of ethnic-group-based relative deprivation (Osborne, Sibley \& Sengupta, 2015).

Second, as in other postcolonial nations, income and ethnic inequality are strongly linked in New Zealand. For example, according to (admittedly older) available census data, Māori make up $14.9 \%$ of the New Zealand population but 
account for $38.5 \%$ of the lowest household-income quartile and only $12.5 \%$ of the highest quartile (Statistics New Zealand, 1996). More recent data show that the proportion of Māori living below the poverty line (60\% of the median household income) is twice that of Europeans (34\% and 17\% respectively; The Social Report, 2014). Further, while incomes among Europeans have increased slightly since 2008, incomes among Māori have dropped sharply (Statistics New Zealand, 2012). This high degree of alignment between ethnic-group and income-inequality in New Zealand means that when New Zealanders see inequality around them, they are apt to interpret in within the context of the clear socio-economic divide that exists along ethnic-group lines. Therefore, it is not difficult to see how people living under greater income inequality might gain a palliative benefit from an ideology that legitimises ethnic-group inequality.

A major strength of our study is its use of large representative samples of both high- and low-status groups, as well as the high number of area units representing abutting regions of New Zealand. The use of a regional-level index of inequality has several advantages over previous analyses in the SJT literature, which have investigated the moderating effects of inequality by using indices of cross-national variation in inequality (e.g. Brandt, 2013; Napier et al., 2010).

First, countries differ on many characteristics other than their levels of inequality, and therefore, tests of the effects of cross-national inequality cannot easily rule out third-variable accounts for the same phenomena (Oishi et al., 2011). Second, the large number of Level 2 units (i.e., neighbourhoods) in our analysis $(\mathrm{N}=1437)$ meant that we had much higher statistical power to test cross-level interactions than previous analyses which have had to rely on between 30 and 65 Level 2 units (i.e., nations; e.g. Naiper \& Jost, 2010). Third, if we are correct, people's responses to 
inequality should not only depend on the overall level of inequality in their nation, but also on the information they get about the inequality in their society from their immediate context. Indeed, people are generally incapable of accurately judging the overall level of inequality in their nation (Norton \& Ariely, 2011), but their subjective perceptions of disadvantage are closely calibrated to the level of inequality in their neighbourhood context (Osborne et al., 2015). Therefore, it becomes important to measure variation in exposure to inequality in people's immediate environment.

\section{Conclusion}

Our results indicate that people living in conditions of inequality feel better about their situation if they are able to ideologically legitimise the group-based hierarchy which characterises their society. This implies that ideology is not just a mechanism to perpetuate inequality, but also a coping mechanism to deal with entrenched inequality. This dual function of ideology can make unequal systems very resistant to change, since those who have the greatest interest in overturning the status quo - those who suffer under the most inequality - also gain the most psychological comfort from legitimising the system. 


\section{References}

Ajwani, S., Blakely, T., Robson, B., Tobias, M., \& Bonne, M. (2003). Decades of disparity: Ethnic mortality trends in New Zealand 1980-1999: Ministry of Health Wellington.

Brandt, M. J. (2013). Do the disadvantaged legitimize the social system? A largescale test of the status-legitimacy hypothesis. Journal of personality and social psychology, 104(5), 765.

Duckitt, J. (2001). A dual-process cognitive-motivational theory of ideology and prejudice. Advances in experimental social psychology, 33, 41-114.

Fehr, E., \& Rockenbach, B. (2003). Detrimental effects of sanctions on human altruism. [10.1038/nature01474]. Nature, 422(6928), 137-140.

Furnham, A. (1982). The Protestant Work Ethic and attitudes towards unemployment. Journal of Occupational Psychology, 55, 277-285. doi:10.1111/j.2044 8325.1982.tb00101.x

Geraci, A., \& Surian, L. (2011). The developmental roots of fairness: infants' reactions to equal and unequal distributions of resources. Developmental Science, 14(5), 1012-1020. doi:10.1111/j.1467-7687.2011.01048.x

Glick, P., \& Fiske, S. T. (2001). An ambivalent alliance: Hostile and benevolent sexism as complementary justifications for gender inequality. American Psychologist, 56(2), 109-118. doi:10.1037/0003-066x.56.2.109

Hafer, C. L., \& Choma, B. L. (2009). Belief in a just world, perceived fairness, and justification of the status quo. In J. T. Jost, A. C. Kay and H. Thorisdottir (Eds.). Social and psychological bases of ideology and system justification (pp. 107-125). Oxford: Oxford University Press. 
Hammond, M., \& Sibley, C. (2011). Why are Benevolent Sexists Happier? Sex Roles, 65(5-6), 332-343. doi:10.1007/s11199-011-0017-2

Henrich, J. (2000). Does Culture Matter in Economic Behavior? Ultimatum Game Bargaining among the Machiguenga of the Peruvian Amazon. The American Economic Review, 90(4), 973-979. doi:citeulike-article-id:482886

Jetten, J., Haslam, S. A., \& Barlow, F. K. (2013). Bringing Back the System: One Reason Why Conservatives are Happier Than Liberals is That Higher Socioeconomic Status Gives Them Access to More Group Memberships. Social Psychological and Personality Science, 4(1), 6-13. doi:10.1177/1948550612439721

Johnson, S. L., Leedom, L. J., \& Muhtadie, L. (2012). The dominance behavioral system and psychopathology: Evidence from self-report, observational, and biological studies. Psychological Bulletin, 138(4), 692-743. doi: $10.1037 / \mathrm{a} 0027503$

Jost, J. T., \& Banaji, M. (1994). The Role of Stereotyping in System-Justification and the Production of False Consciousness. British Journal of Social Psychology, $22,1-27$.

Jost, J. T., Burgess, D., \& Mosso, C. O. (2001). 15 Conflicts of Legitimation among Self, Group, and System. The psychology of legitimacy: Emerging perspectives on ideology, justice, and intergroup relations, 363.

Jost, J. T., Federico, C. M., \& Napier, J. L. (2009). Political Ideology: Its Structure, Functions, and Elective Affinities. Annual Review of Psychology, 60(1), 307337. doi:doi:10.1146/annurev.psych.60.110707.163600 
Jost, J. T., \& Hunyady, O. (2005). Antecedents and Consequences of SystemJustifying Ideologies. Current Directions in Psychological Science, 14(5), 260-265. doi:10.1111/j.0963-7214.2005.00377.x

Jost, J. T., Pelham, B. W., Sheldon, O., \& Ni Sullivan, B. (2003). Social inequality and the reduction of ideological dissonance on behalf of the system: evidence of enhanced system justification among the disadvantaged. European Journal of Social Psychology, 33(1), 13-36. doi:10.1002/ejsp.127

Jost, J. T., \& Thompson, E. P. (2000). Group-Based Dominance and Opposition to Equality as Independent Predictors of Self-Esteem, Ethnocentrism, and Social Policy Attitudes among African Americans and European Americans. Journal of Experimental Social Psychology, 36(3), 209-232. doi:http://dx.doi.org/10.1006/jesp.1999.1403

Jost, J. T., Wakslak, C. J., \& Tyler, T. R. (2008). System justification theory and the alleviation of emotional distress: Palliative effects of ideology in an arbitrary social hierarchy and in society. Advances in Group Processes, 25, 181-211.

Kahneman, D., Knetsch, J. L., \& Thaler, R. H. (1991). Anomalies: The endowment effect, loss aversion, and status quo bias. The journal of economic perspectives, 193-206.

Kay, A. C., Jost, J. T., \& Young, S. (2005). Victim derogation and victim enhancement as alternate routes to system justification. Psychological Science, 16(3), 240-246. doi:10.1111/j.0956-7976.2005.00810.x

Kinder, D. R. \& Sears, D. O. (1981). Prejudice and politics: Symbolic racism versus racial threats to the good life. Journal of Personality and Social Psychology, 40, 414-431. doi: $10.1037 / 0022-3514.40 .3 .414$

King, M. (2007). The Penguin history of New Zealand. North Shore, NZ: Penguin. 
Kluegel, J. R., \& Smith, E. R. (1986). Beliefs about inequality: American's view of what is and what ought to be. Hawthorne, NJ: Aldine de Gruyer.

Laurin, K., Fitzsimons, G. M., \& Kay, A. C. (2011). Social disadvantage and the selfregulatory function of justice beliefs. Journal of personality and social psychology, 100(1), 149-171.

Lerner, M. J. (1980). The belief in a just world: A fundamental delusion. New York, NY: Plenum Press.

Major, B. (1994). From social inequality to personal entitlement: The role of social comparisons, legitimacy appraisals, and group membership. Advances in experimental social psychology, 26, 293-293.

Major, B., Gramzow, R. H., McCoy, S. K., Levin, S., Schmader, T., \& Sidanius, J. (2002). Perceiving personal discrimination: The role of group status and legitimizing ideology. Journal of Personality and Social Psychology, 82(3), 269-282. doi:10.1037/0022-3514.82.3.269

Marx, K (1844). A Contribution to the Critique of Hegel's Philosophy of Right. Deutsch-Französische Jahrbücher.

McCoy, S. K., \& Major, B. (2007). Priming and the psychological justification of inequality. Journal of Experimental Social Psychology, 43(3), 341-351. doi:10.1016/j.jesp.2006.04.009

McCoy, S. K., Wellman, J. D., Cosley, B., Saslow, L., \& Epel, E. (2013). Is the belief in meritocracy palliative for members of low status groups? Evidence for a benefit for self-esteem and physical health via perceived control. European Journal of Social Psychology, 43(4), 307-318. doi:10.1002/ejsp.1959

Napier, J., Thorisdottir, H., \& Jost, J. (2010). The Joy of Sexism? A Multinational Investigation of Hostile and Benevolent Justifications for Gender Inequality 
and Their Relations to Subjective Well-Being. Sex Roles, 62(7-8), 405-419. doi:10.1007/s11199-009-9712-7

Napier, J. L., \& Jost, J. T. (2008). The “Antidemocratic Personality” Revisited: A Cross-National Investigation of Working-Class Authoritarianism. Journal of Social Issues, 64(3), 595-617.

O’Brien, L. T., \& Major, B. (2005). System-Justifying Beliefs and Psychological Well-Being: The Roles of Group Status and Identity. Personality and Social Psychology Bulletin, 31(12), 1718-1729. doi:10.1177/0146167205278261

Onraet, E., Van Hiel, A., \& Dhont, K. (2013). The relationship between right-wing ideological attitudes and psychological well-being. Personality and Social Psychology Bulletin, doi:10.1177/0146167213478199

Osborne, D., \& Sibley, C. G. (2013). Through Rose-Colored Glasses: SystemJustifying Beliefs Dampen the Effects of Relative Deprivation on Well-Being and Political Mobilization. Personality and Social Psychology Bulletin. doi:10.1177/0146167213487997

Osborne, D., Sibley, C. G. \& Sengupta, N. K. (2015). Income and neighbourhoodlevel inequality predict self-esteem and ethnic identity centrality through individual- and group-based relative deprivation: A multi-level path analysis. European Journal of Social Psychology, 45,368-377.

Petersen, M. B. (2015). Evolutionary Political Psychology: On the Origin and Structure of Heuristics and Biases in Politics. Political Psychology, 36, 45-78. doi: $10.1111 /$ pops. 12237

Piketty, T. (2014). Capital in the Twenty-first Century: Harvard University Press.

Quinn, D. M., \& Crocker, J. (1999). When ideology hurts: Effects of belief in the Protestant ethic and feeling overweight on the psychological well-being of 
women. Journal of personality and social psychology, 77(2), 402-414. doi:10.1037/0022-3514.77.2.402

Rankin, L. E., Jost, J. T., \& Wakslak, C. J. (2009). System justification and the meaning of life: Are the existential benefits of ideology distributed unequally across racial groups? Social Justice Research, 22(2-3), 312-333. doi:10.1007/s11211-009-0100-9

Reicher, S. (2007). Rethinking the paradigm of prejudice. South African Journal of Psychology, 37, 820-834. doi:10.1111/j.1467-9221.2004.00403.x

Schlenker, B. R., Chambers, J. R., \& Le, B. M. (2012). Conservatives are happier than liberals, but why? political ideology, personality, and life satisfaction. Journal of Research in Personality, 46(2), 127-146. doi:http://dx.doi.org/10.1016/j.jrp.2011.12.009

Sears, D. O., \& Henry, P. J. (2003). The origins of symbolic racism. Journal of personality and social psychology, 85, 259-275.

Sears, D. O., \& Henry, P. J. (2005). Over thirty years later: A contemporary look at symbolic racism. Advances in experimental social psychology, 37, 95-150.

Sengupta, N. K., Greaves, L., Osborne, D., Milojev, P. \& Sibley, C. G. (2014). Neighborhood inequality and wellbeing in New Zealand. Unpublished Manuscript.

Sengupta, N. K., Osborne, D., \& Sibley, C. G. (2015). The status-legitimacy hypothesis revisited: Ethnic-group differences in general and dimensionspecific legitimacy. British Journal of Social Psychology. 54, 324-340. doi:10.1111/bjso. 12080

Sengupta, N. K. \& Sibley, C. G. (2014). Status-legitimacy effects in areas with high inequality. Unpublished Manuscript. 
Sibley, C. G., \& Wilson, M. S. (2007). Political Attitudes and the Ideology of Equality: Differentiating Support for Liberal and Conservative Political Parties in New Zealand. New Zealand Journal of Psychology, 36(2), 72-84.

Sidanius, J., \& Pratto, F. (1999). Social dominance: An intergroup theory of social hierarchy and oppression. New York, NY, US: Cambridge University Press.

Sloane, S., Baillargeon, R., \& Premack, D. (2012). Do Infants Have a Sense of Fairness? Psychological Science. doi:10.1177/0956797611422072

Smith, H. J., \& Tyler, T. R. (1996). Justice and power: when will justice concerns encourage the advantaged to support policies which redistribute economic resources and the disadvantaged to willingly obey the law? European Journal of Social Psychology, 26(2), 171-200. doi:10.1002/(sici)1099-0992

The Social Report (2010). Wellington, NZ: Ministry of Social Development. Retrieved from http://socialreport.msd.govt.nz/

van der Toorn, J., Berkics, M., \& Jost, J. (2010). System Justification, Satisfaction, and Perceptions of Fairness and Typicality at Work: A Cross-System Comparison Involving the U.S. and Hungary. Social Justice Research, 23(23), 189-210. doi:10.1007/s11211-010-0116-1

van Zomeren, M., Spears, R., Fischer, A. H., \& Leach, C. W. (2004). Put your money where your mouth is!: Explaining collective action tendencies through groupbased anger and group efficacy. Journal of Personality and Social Psychology, 87, 649-664.

Wakslak, C. J., Jost, J. T., Tyler, T. R., \& Chen, E. S. (2007). Moral outrage mediates the dampening effect of system justification on support for redistributive social policies. Psychological Science, 18(3), 267-274. 
Walker, R. (1990). Ka whawhau tonu (Struggle without end). Auckland: Penguin Books.

Wilkinson, R., \& Pickett, K. (2009). The spirit level: Why greater equality makes societies stronger: Bloomsbury Publishing USA.

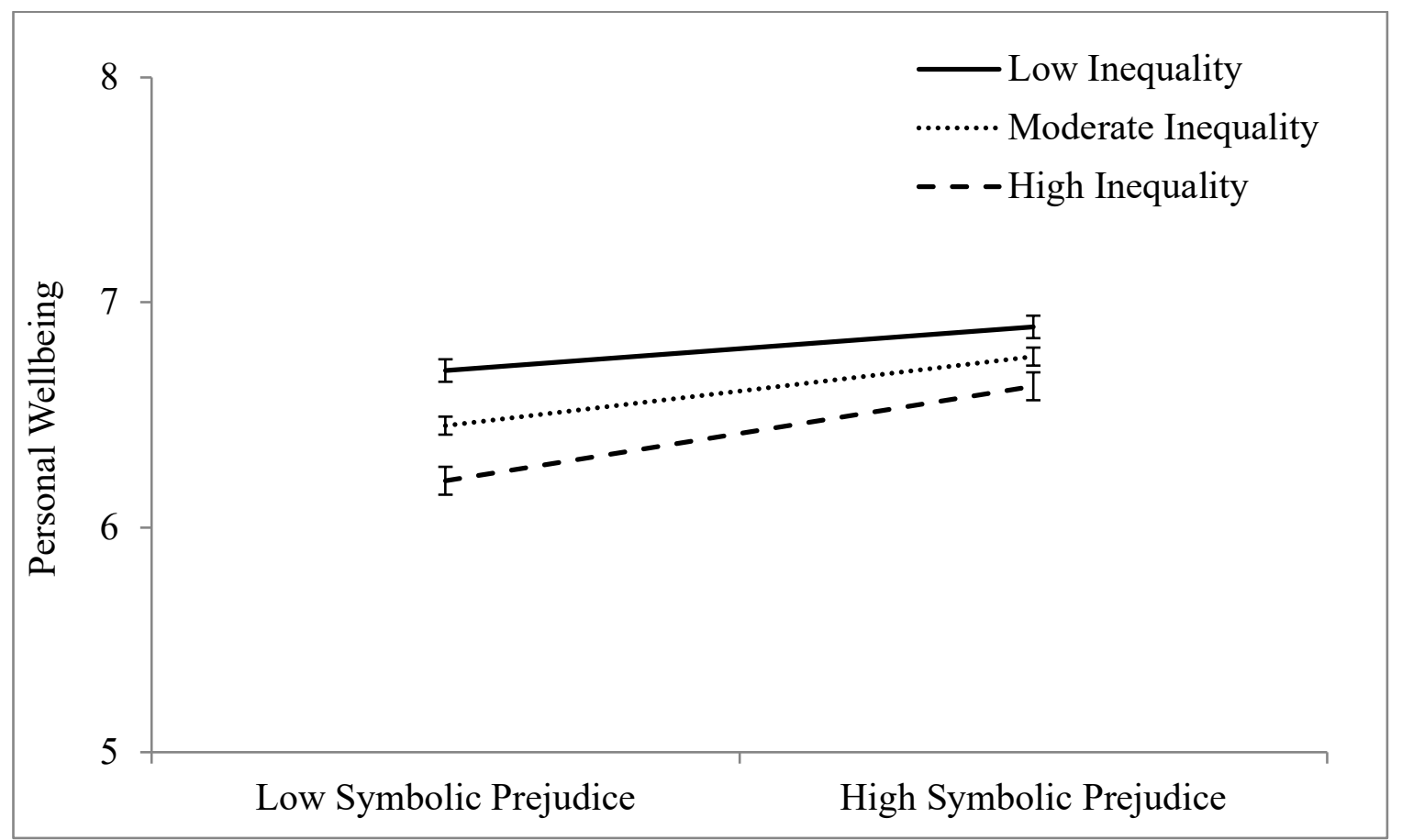

Figure 1. Line graph showing the relationship between Symbolic Prejudice and Personal Wellbeing in neighbourhoods with low, moderate and high levels of inequality. 
Table 1. Descriptive statistics and correlations between all variables at Level 1.

\begin{tabular}{lccccccc}
\hline & 1. & 2. & 3. & 4. & 5. & 6. & 7. \\
\hline 1. Age & - & & & & & & \\
2. Gender & $.09^{*}$ & - & & & & & \\
3. Education & $-.15^{*}$ & $-.09^{*}$ & - & & & & \\
4. Income (log) & $-.18^{*}$ & $.05^{*}$ & $.30^{*}$ & - & & & \\
5. Ethnicity & $-.13^{*}$ & -.01 & $-.15^{*}$ & $-.11^{*}$ & - & & \\
6. Symbolic Prejudice & $.07^{*}$ & $.09^{*}$ & $-.20^{*}$ & -.02 & $-.24^{*}$ & - & \\
7. Personal Wellbeing & $.07^{*}$ & $-.03^{*}$ & $.11^{*}$ & $.25^{*}$ & $-.15^{*}$ & $.08^{*}$ & - \\
& & & & & & & \\
$M$ & 47.97 & .40 & -.36 & 11.08 & .19 & 5.14 & 6.59 \\
$S D$ & 15.78 & .49 & 1.30 & .78 & .40 & 1.43 & 1.81 \\
\hline
\end{tabular}

Note. ${ }^{*} \mathrm{p}<.01$. 
Table 2. Regression coefficients for the multi-level model predicting personal wellbeing

\begin{tabular}{|c|c|c|c|c|c|c|}
\hline & \multirow[t]{2}{*}{$\mathrm{b}$} & \multirow[t]{2}{*}{ se } & \multicolumn{2}{|c|}{$95 \% \mathrm{CI}$} & \multirow[t]{2}{*}{$\mathrm{z}$} & \multirow[t]{2}{*}{$\mathrm{p}$} \\
\hline & & & low & high & & \\
\hline Intercept & 6.605 & .029 & 6.549 & 6.662 & & \\
\hline Age & .011 & .002 & .008 & .015 & 6.175 & .000 \\
\hline Gender & -.157 & .052 & -.259 & -.055 & -3.023 & .003 \\
\hline Education & .102 & .022 & .059 & .145 & 4.663 & .000 \\
\hline Income $(\log )$ & .589 & .048 & .494 & .684 & 12.188 & .000 \\
\hline Area population & .000 & .017 & -.033 & .033 & -.010 & .992 \\
\hline Ethnicity & -.332 & .077 & -.482 & -.182 & -4.332 & .000 \\
\hline Symbolic Prejudice & .124 & .020 & .085 & .164 & 6.156 & .000 \\
\hline Regional inequality & -3.770 & .592 & -4.930 & -2.610 & -6.370 & .000 \\
\hline Symbolic Prejudice $x$ Ethnicity & .082 & .057 & -.030 & .194 & 1.435 & .151 \\
\hline Inequality $\mathrm{x}$ Ethnicity & -.357 & 1.854 & -3.991 & 3.277 & -.193 & .847 \\
\hline Inequality x Symbolic Prejudice & .912 & .443 & .044 & 1.780 & 2.059 & .040 \\
\hline Inequality $\mathrm{x}$ Symbolic Prejudice $\mathrm{x}$ Ethnicity & 2.902 & 1.516 & -.069 & 5.874 & 1.915 & .056 \\
\hline
\end{tabular}

Note. $\mathrm{N}=5,592$ participants, $\mathrm{N}=1,432$ regions, average cluster size $=3.905$, ICC for outcome $=.038, \log$ likelihood $=-11037$, AIC $=$ $22110, \mathrm{BIC}=22229$.

${ }^{1}$ Further information about the NZAVS, along with all technical documentation can be found at https://www.psych.auckland.ac.nz/en/about/our-research/research-groups/new-zealand-attitudes-andvalues-study.html 